\title{
¿Un viejo centro, para nuevos usos? Distribución espacial de Servicios Intensivos en Conocimiento [SIC] en el Área Metropolitana de Concepción [AMC], Chile
}

\section{Aaron Napadensky Pastene ${ }^{1}$}

Recibido: 10-02-2020 | en su versión final: 29-06-2020

Resumen

En el contexto del interés que están tomando las ciudades medias en la búsqueda de sistemas urbanos más equilibrados (Diez \& Emilozzi, 2015), la pesquisa tuvo como objetivo central el discutir y relativizar la aplicabilidad a priori de consensos académicos predominantes sobre metropolización, polinucleación y tercerización, al análisis y comprensión de sistemas urbanos intermedios. Con este fin se caracterizó las tendencias recientes de localización y distribución espacial de servicios terciarios en general, y SIC en particular, para el Área Metropolitana de Concepción (AMC), Chile, levantando una base de datos con las patentes comerciales emitidas por los municipios durante 5 años (2012-2016), esto para las once comunas que conforman la metrópolis. Posteriormente se procedió a depurar las bases, homologando las categorías locales a las internacionales (Glossary: Knowledge-Intensive Service), información que fue georreferenciada con el software Arcgis 10.2., analizando, contrastando e interpretando sus resultados. Finalmente se concluye, que ni las sub-centralidades comerciales, ni las periferias industriales, han sido factores relevantes para explicar la distribución de los SIC en el AMC, siendo la centralidad tradicional y los barrios de altos ingresos adyacentes, lo que mejor explican sus localizaciones, concentraciones y expansiones. El principal hallazgo, identificó un cambio en el eje funcional terciario del núcleo central del AMC, históricamente conformado por las comunas de Concepción y Talcahuano, a un nuevo eje central conformado por Concepción y San Pedro de la Paz, dando cuenta de una emergente reestructuración, guiada, en buena parte, por la proximidad y atributos medioambientales y paisajísticos de esta última comuna.

Palabras clave: Metrópolis intermedias; centros tradicionales; tercerización económica; localización

Citación

Napadensky, A. (2020). ¿Un viejo centro, para nuevos usos? Distribución espacial de Servicios Intensivos en Conocimiento [SIC] en el Área Metropolitana de Concepción [AMC], Chile. ACE: Architecture, City and Environment, 15(44), 9210. DOl: http://dx.doi.org/10.5821/ace.15.44.9210

\footnotetext{
1 Dr. Arquitecto, Director del Laboratorio de Estudios Urbanos, Departamento de Planificación y Diseño Urbano, Universidad del Bío Bío, Chile. (ORCID: 0000-0002-8851-7201; WoS ResearcherID: ABB-3160-2020; Scopus author ID: $\underline{\text { 57194977620). Correo de contacto: anapaden@ubiobio.cl }}$
} 


\title{
An old downtown, for new uses? Spatial distribution of knowledge-intensive services [KIS] in the Concepción Metropolitan Area [AMC], Chile
}

\begin{abstract}
In the context of the interest that middle cities are taking in the search for more balanced urban systems (Diez \& Amilozzi, 2015), the research had as its main objective to discuss and relativize the a priori applicability of predominant academic consensus on metropolization, polynucleation, and outsourcing, analysis, and understanding of intermediate urban systems. In order to characterize the recent trends in location and spatial distribution of tertiary services in general, and Knowledge-Intensive Service (KIS) in particular, for the Metropolitan Area of Concepción (AMC), Chile, a database was created with the commercial patents issued by the municipalities. For 5 years (2012-2016), this for each commune that makes up the metropolis. Subsequently, the bases were filtered, standardizing the local categories to the international ones (Glossary: Knowledge-Intensive Service), information that was georeferenced with the Arcgis 10.2 software, analyzing, contrasting, and interpreting its results. Finally, it is concluded that neither the commercial sub-centralities nor the industrial peripheries have been relevant factors in explaining the distribution of KISs in the AMC, with the downtown being the one that best explains their locations, concentrations, and expansions. The main finding identified a change in the functional axis of the central core of the AMC, historically formed by the Concepción and Talcahuano, to a new central axis formed by Concepción and the San Pedro de la Paz, accounting for an emerging restructuring, guided by the proximity, environmental and landscape attributes of this last commune.
\end{abstract}

Keywords: Intermediate metropolis; downtown; tertiary services and location

\section{Introducción}

En el último tercio del siglo XX, la visión neoliberal llegó a Latinoamérica, promoviendo desregulación económica, privatización de servicios públicos y una general retirada del Estado regulador (Meyer \& Bähr, 2001), resultando nuevas formas de urbanización y organización, que han respondido cada vez más a las lógicas neoliberales de comercialización y generación de valor, que a la proyección centralizada de un ideario de ciudad (Janoschka, 2002), replicando en las grandes ciudades del continente, tendencias observadas en países industrializados. Tendencias que han sido profusamente estudiadas bajo distintos nombres; edge-cities (Garreau, 1991), o exópolis (Soja, 2008), entre otras, destacando con ello, un estadio de relevo sobre un primer momento de conformación y generalización de las unidades funcionales devenidas de la intensificación de las relaciones dentro de las propias ciudades y de estas con los centros urbanos próximos, es decir, las metrópolis (Gaussier, Lacour \& Puissant, 2003). Cambios que, pese a los distintos énfasis y enfoques, en términos generales, dan cuenta de la dispersión y consolidación de un modelo policéntrico y de borde, en detrimento de las históricas centralidades metropolitanas, tal como estaría sucediendo en las grandes capitales latinoamericanas (Ciccolella, 1999; De Mattos, 1999).

Continentalmente, esta latino-metropolización avanzada, afincada principalmente en las capitales nacionales, fue caracterizándose por una organización y estructuración polinuclear, sustentada principalmente por dos tendencias: (i) la maduración de los capitales inmobiliarios y modernización 
de la industria del comercio detallista, surgiendo grandes operadores de retail, que introdujeron y apropiaron la tipología shopping mall, creando subcentralidades comerciales de gran peso y relevancia en las estructuras funcionales metropolitanas (Napadensky, 2012); y (ii) por la expansión y éxodo de las actividades económicas terciarias de los centros tradicionales metropolitanos (Aguilar, 2002; De Mattos, 2010).

Ambas condiciones, han venido diluyendo tras de sí las tradicionales formas de organización funcional metropolitana (Janoschka, 2002; Meyer \& Bähr, 2001; Cabrales \& Canosa, 2002), creando nuevos enclaves de consumo y servicios avanzados fuera de las tradicionales centralidades fundacionales (Aguilar, 2002; Cicolella, 1999; De Mattos, 2002). Ejemplo de esto último, son los casos de Ciudad de México, con los centros de servicios de Santa Fe y el Bosque (Parnreiter, 2002, 2005, 2011), Lima y su distrito financiero de San Isidro (Chion, 2002), Buenos Aires, con el eje norte y el barrio del Pilar (Ciccolella, 1999); o Santiago y el eje oriente de Las Condes-Vitacura, y la Ciudad Empresarial de Huechuraba (Ducci, 2000), por nombrar algunos.

Ambos fenómenos urbanos, no solo han sido emparentados, en cuanto a que los servicios terciarios siguen las sub-centralidades de consumo, fortaleciéndose mutuamente (De Mattos, 2010; Vecslir \& Ciccolella, 2011), sino también porque ambas tendencias han sido acusadas de precipitar la obsolescencia funcional de los centros tradicionales (Sarlo, 1994, 2006; Janoschka, 2002; Artigas, et al., 2002; Carman, 2006; López-Levi,1997, 1999; Eerola, 2006). Estos discursos académicos relativamente consensuados, se constituyeron desde el estudio de las grandes capitales nacionales, sin embargo, no son pocas las veces en que son utilizados como argumentos analíticos de aproximación a las lógicas de metropolización en urbes intermedias, bajo el entendido que son estadios previos y que inevitablemente confluirían a un mismo proceso de reordenamiento funcional y estructuración urbana; sumergiendo con ello posibles singularidades que pueden escapar a una simple cuestión escalar o evolutiva.

En el contexto de lo dicho, relevante es estudiar las tendencias localizacionales de servicios terciarios en general, e intensivos en conocimiento en particular, en una metrópolis que no es capital nacional, que por lo mismo puede definirse como metrópolis intermedia, y cuyo origen fue una conurbación industrial de ciudades intermedias, explorando y problematizando en torno a las concomitancias y deslindes entre lo aquí observado y los discursos predominantes. Para ello, el trabajo se focalizó en el Área Metropolitana de Concepción (AMC), Chile, discutiendo si existen indicios que van en consonancia a los discursos expuestos, o, por el contrario, emergen antecedentes que hagan sospechar cambios y tendencias que escapen a dichos consensos.

La discusión se inicia explicitando las narrativas académicas predominantes, posteriormente se tensionan estos discursos y su aplicabilidad a sistemas urbanos intermedios, a través de la exploración e interpretación de una serie de cartografías que muestran las tendencias de dispersión-concentración de los Servicios Intensivos en Conocimiento (SIC), según la local homologación a las cuatro categorías internacionalmente definidas para estos servicios, y su correlato con la morfología estructural del AMC (la homologación se realiza sobre una tabla de datos, conformada por las patentes comerciales efectivamente otorgadas por los 11 municipios del AMC, entre 2012-2016). Cabe señalar que, de las cuatro categorías, cada una conformada por una serie de sub-categorías, se seleccionaron dos, por su notables volumen en el periodo de estudio, las que también se cartografían a fin de bajar aún más el lente de discusión. Los resultados estuvieron en dos escalas de análisis urbano, una metropolitana y otra comunal'.

\footnotetext{
1 La comuna o municipio suelen usarse de forma indistinta, sin embargo, mientras la primera acepción alude a la unidad espacial de limites político-administrativos, la segunda atañe al gobierno de dicha unidad. El municipio sería el símil al ayuntamiento en el caso español. En esta misma lógica operativa, cada comuna está compuesta u operativamente dividida en distritos censales, unidad espacial menor que suele utilizarse para representar datos del Censo Nacional.
} 
En lo comunal se identificó que, lejos de aportar a su obsolescencia, las tendencias locacionales de los SIC, renuevan y dan vigencia al centro tradicional de Concepción, capital regional, intensificando y expandiendo su presencia, observándose una dialéctica transformadora entre estos y la morfología funcional del microcentro comercial, el cual se expande hacia los barrios pericentrales, de Pedro de Valdivia (Distrito Censal, 50. Observatorio) y Barrio Universitario (Distrito Censal, 48. Lopequen), históricos sectores residenciales de altos ingresos. Junto a lo descrito, y ya en la escala metropolitana, se consigna la vigencia del histórico núcleo funcional central pero se hace un hallazgo, hasta ahora no documentado, identificando una tendencia de cambio en el eje funcional de este núcleo central del AMC, históricamente conformado por los centros tradicionales y conurbaciones funcionales de Concepción y Talcahuano, a un nuevo eje central conformado por Concepción y San Pedro de la Paz, comuna que ha experimentado un importante crecimiento residencial, con sustanciales enclaves de altos ingresos, capitalizado la belleza escénica, atractivos naturales y oferta gastronómico-recreativa aquí existentes, pero que ahora también evidencia un importante crecimiento en servicios intensivos en conocimiento. Finalmente se establecen conclusiones y nuevas interrogantes.

\section{Propuesta metodológica}

Con el fin de caracterizar las tendencias recientes de localización y distribución espacial de los SIC dentro del AMC, se levantó una base de datos con las patentes comerciales emitidas por los municipios durante 5 años (2012-2016), esto por cada uno de las 11 comunas que conforman la metrópolis. En fase posterior, se procedió a trabajar las bases, homologando las categorías locales a las internacionales de Servicios Intensivos en Conocimiento. En este sentido se consideró relevante la patente comercial, porque a diferencia de la creación de empresas, que en muchos casos informan direcciones particulares, especialmente en el caso de empresas unipersonales, la patente comercial, exige una dirección comercial, que es más clara en evidenciar tendencias locacionales, y al estar asociada a un pago, hace suponer su efectiva iniciación de actividades.

Con las bases de datos ya homologada, se construyó un catastro único metropolitano con las categorías del sistema estadístico europeo (Eurostat (s/f): Statistic Explained. Glossary: KnowledgeIntensive Service), el cual clasifica los SIC en cuatro grupos, cada uno compuesto por otras subcategorías, en: (i) Servicios con uso intensivo de conocimiento y tecnología avanzada (ST); (ii) Servicios con uso intensivo de conocimiento orientados al mercado y las empresas (exceptuando servicios de intermediación financiera) (SM); (iii) Servicios financieros con uso intensivo de conocimiento (SF); y (iv) Otros servicios intensivos en conocimiento (SO). De todas las subcategorías, se seleccionaron aquellas que, en el periodo en cuestión, fueron las de mayor dinamismo y creación de emprendimiento, que, para el caso de estudio, fue; Arquitectura e Ingeniera (71), y Servicios Jurídicos y contabilidad (69), ambas de la categoría SM. Aquellos tipos de patentes que no fue posible homologar, se clasificaron como NO-SIC. (Tabla 1)

Del total de patentes comerciales levantadas en el AMC, para el periodo, 11.690, solo 1.805 fueron homologables a una de las cuatro categorías de SIC, el resto quedó como categoría NO-SIC, es decir servicios terciarios no intensivos en conocimiento. Después de procesada la tabla de datos, se ingresó la información en el software Arcgis 10.2, donde fueron georreferenciadas según distrito censal (DC), unidad espacial operativa que divide las comunas), generando intensidades de color según concentración por unidad. La elección de este método fue por su facilidad de maximizar las diferencias entre unidades espaciales, expresando gráficamente con mayor claridad las tendencias de localización. Los resultados de las patentes homologadas y sus direcciones georreferenciadas, se corroboraron con los sitios web, openstreetmaps y googlemaps, resultando 1619 patentes corroboradas con éxito, lo que dio una efectividad del 90\%. Luego de este último paso, se

ACE, 15 (44) CC BY-ND 3.0 ES | UPC Barcelona, España | ¿Un viejo centro, para nuevos usos? Distribución 
generaron cartografías para cada una de las 4 categoría SIC, y para las dos subcategorías más demandadas. Esto se consideró relevante para su interpretación y discusión.

Para caracterizar las comunas del AMC, junto con población e ingresos por hogar, éstas se clasificaron según su distancia al centro en, comunas: (i) Centrales, Concepción y Talcahuano; (ii) Pericentrales, San Pedro de la Paz, Chiguayante, Hualpén, Penco; y (iii) periféricas, Coronel, Lota, Tomé, Hualqui y Santa Juana. (Figura 1). Con las cartografías del área metropolitana, se identificaron las comunas que más concentraban SIC, coincidiendo con las comunas centrales del AMC. Finalmente, y a la luz de los antecedentes teóricos expuestos, se genera un contrapunto entre ellos y los resultados cartográficos del caso, interpretando y abriendo nuevas interrogantes sobre el devenir del AMC en particular, y de los sistemas urbanos intermedios en general. Pese a lo pertinente que se considera la metodología para revisar la tendencia de localización de este tipo de servicios en un contexto espacial y periodo determinado, existen limitantes insoslayables; la primera es que pese a lo interesante que hubiese sido un análisis multi-temporal, los datos obtenidos en los 11 municipios del AMC, antes del 2012, presentan desiguales formatos, y algunas tampoco disponen de todos los datos, dificultando su homologación, por lo que se consideró el 2012, como año de inicio. Otro punto a considerar, es que acá se está hablando de una tendencia de localización, concentración-dispersión, en el mérito del periodo en cuestión, independiente del tamaño de la empresa y el número de trabajadores que estos emprendimientos contemplan.

Tabla 1. Clasificación de Servicios Intensivos en Conocimiento [KIS]

\begin{tabular}{|c|c|}
\hline \multirow{5}{*}{$\begin{array}{l}\text { Servicios con uso intensivo de } \\
\text { conocimiento y tecnología } \\
\text { avanzadas (ST) }\end{array}$} & $\begin{array}{l}\text { (59) Actividades cinematográficas, de video y de programas de televisión, } \\
\text { grabación de sonido y edición musical. }\end{array}$ \\
\hline & (61) Telecomunicaciones \\
\hline & $\begin{array}{l}\text { (62) programación informática, consultoría y otras actividades relacionadas } \\
\text { con la informática }\end{array}$ \\
\hline & (63) Servicios de información \\
\hline & (72) Investigación y desarrollo \\
\hline \multirow{9}{*}{$\begin{array}{l}\text { Servicios con uso intensivo de } \\
\text { conocimiento orientados al } \\
\text { mercado y las empresas } \\
\text { (excepto servicios de } \\
\text { intermediación financiera) (SM) }\end{array}$} & (50) Transporte marítimo y por vías navegables interiores \\
\hline & (51) Transporte aéreo \\
\hline & (69) Actividades jurídicas y de contabilidad \\
\hline & $\begin{array}{l}\text { (70) Actividades de las sedes centrales; actividades de consultoría y análisis } \\
\text { técnico }\end{array}$ \\
\hline & (71) Servicios técnicos de arquitectura e ingeniera; ensayos y análisis técnicos \\
\hline & (73) Publicidad y estudios de mercado \\
\hline & (74) Otras actividades profesionales, científicas y técnicas \\
\hline & (78) Actividades relacionadas con el empleo \\
\hline & (80) Actividades de seguridad e investigación \\
\hline \multirow{3}{*}{$\begin{array}{l}\text { Servicios financieros con uso } \\
\text { intensivo de conocimiento (SF) }\end{array}$} & (64) Servicios financieros, excepto seguros y fondos de pensiones \\
\hline & $\begin{array}{l}\text { (65) Seguros, reaseguros y fondos de pensiones, excepto seguridad social } \\
\text { obligatoria }\end{array}$ \\
\hline & (66) Actividades auxiliares a los servicios financieros y a los seguros \\
\hline \multirow{10}{*}{$\begin{array}{l}\text { Otros servicios intensivos en } \\
\text { conocimiento (SO) }\end{array}$} & (58) Actividades de edición \\
\hline & (75) Actividades veterinarias \\
\hline & (84) Administración pública y defensa \\
\hline & (85) Educación \\
\hline & (86) Actividades sanitarias \\
\hline & (88) Actividades de servicios sociales sin alojamiento \\
\hline & (90) Actividades de creación, artísticas y espectáculos \\
\hline & $\begin{array}{l}\text { (91) Actividades de bibliotecas, archivos, museos y otras actividades } \\
\text { culturales }\end{array}$ \\
\hline & (92) Actividades de juegos de azar y apuestas \\
\hline & (93) Actividades deportivas, recreativas y de entrenamiento \\
\hline
\end{tabular}

Fuente: Eurostat, Statistic Explained. Glossary: Knowledge-Intensive Service (KIS) Disponible en https://ec.europa.eu/eurostat/statistics-explained/index.php/Glossary:Knowledge-intensive services (KIS) 


\section{Servicios intensivos en conocimiento, metropolización y estructuras urbanas polinucleares}

A fines del siglo pasado, ya se consensuaba e indicaba al crecimiento del mercado de servicios avanzados, como uno de los principales responsables del auge y nuevas dinámicas metropolitanas observables en las principales capitales globales (Veltz, 1994; Sassen, 1996). Por lo mismo se viene hablando de una nueva economía del conocimiento, creatividad e innovación, levantando una serie de clasificaciones y definiciones; ejemplo de esto son conceptos como, industrias creativas ${ }^{2}$ (Howkins, 2001) o clase creativa ${ }^{3}$ (Florida, 2010), aproximaciones no exentas de controversias y debate (Hoyman \& Faricy, 2008; Jurarte, 2011; Brenner \& Theodore, 2002; Harvey, 2005; Peck, 2005; Krätke, 2011). Algo más alejado de la polémica, y más centrados en medir la intensidad en el uso del conocimiento, característica diferencial de los servicios avanzados (García, 2008), están los así llamados Servicios Intensivos en Conocimiento (SIC), o su acrónimo inglés, KIS, Knowledge Intensive Services ${ }^{4}$ (Eurostat Regional Year Book, 2014).

Los KIS o SIC, son considerados, al menos en las economías más industrializadas, los componentes más dinámicos de las economías urbanas (García, 2008; Muller \& Zenker, 2001), factores decisivos en los procesos de reestructuración urbana y crecimiento económico de las regiones, enfatizando el rol de las metrópolis como plataformas críticas para capitalizar el capital humano en capital intelectual colectivo, promoviendo desarrollo y competencias de mercado (Vence, 2007; Vence \& Rodil, 2003; Martinelli \& Cavola, 2002; Muller \& Zenker, 2001; Costas, 2008; Pratt, 2008; Throsby, 2004, 2008). Son, por lo mismo, de gran importancia, relevancia y estudio en la geografía económica reciente.

En la literatura especializada, se reconocen patrones diferenciados de dispersión-concentración de los servicios, estos en términos generales, tienden a seguir la regla de, a menor especialización, mayor distribución en el territorio, desconcentrándose con mayor facilidad; en contrapartida, cuanto más especializados son, más intensa puede ser su concentración espacial. Así, los SIC, suelen estar intensamente concentrados en torno a regiones metropolitanas, particularmente capitales nacionales (Vence \& Rodil, 2003), y dentro de estas, como ya se dijo, tenderían a concentrarse más que el resto de las actividades no-SIC (Muñiz-Olivera \& García-López, 2009), tendencia que se vería influenciada por distintas variables, reconociéndose entre las principales; presencia de áreas centrales, clusters económicos, centros de investigación, universidades, o entornos industriales terciarios (Berry \& Glaeser, 2005; Wolfe \& Gertler, 2004; Gertler \& Vinodrai, 2005). Confirmando una general tendencia de dispersión aglomerada, alrededor de lugares con ventajas competitivas, como las ya mencionadas, fortaleciendo y consolidando el policéntrismo metropolitano (Chica y Marmolejo, 2011). Sin embargo, esto también presenta distingo dependiendo la categoría de SIC, por ejemplo, los de alta tecnología, tienden, por sobre las demás categorías, a localizarse en torno a zonas de gran peso industrial, relacionadas a grandes capitales (Vence \& Rodil, 2003; Martinelli \& Cavola, 2002; García, 2008).

\footnotetext{
2 Las industrias creativas se clasifican en: i) Innovación más desarrollo, I+D; ii) Sector editorial; iii) Programas informáticos; iv) TV y radio; v) Diseño; vi) Música; vii) Cine; viii) Juegos y juguetes; ix) Publicidad; x) Arquitectura; xi) Artes escénicas; xii) Video juego; xiii) Moda; y xiv) Arte.

3 La clase creativa, estaría conformada por: (i) Informática y matemáticas; (ii) Arquitectura y las distintas ingenierías; (iii) Ciencias sociales, físicas y de la vida; (iv) Educación, enseñanza y lectura; (v) Arte, diseño, entretenimiento deporte y medios de comunicación. Y los Profesionales creativos: (i) Puestos de alta dirección; (ii) Empresa y finanzas; (iii) Sector jurídico; (iv) Profesiones sanitarias y técnicas; (v) Ventas alto nivel y gestión ventas.

${ }^{4}$ El sistema estadístico europeo (EUROSTAT, 2014), clasifica los KIS en: (i) Servicios intensivos en conocimiento de alta tecnología; (ii) Servicios de mercado intensivo en conocimiento; (iii) Servicios financieros intensivos en conocimiento; y (iv) Otros servicios intensivos en conocimiento.
} 
Sin embargo, y pese a lo dicho, la trayectoria específica de cada ciudad, condicionaran las posibilidades de desarrollar nuevos perfiles económicos como los aquí comentados, siendo difícilmente generalizar (Sánchez, 2012), dando cuenta con ello factores endógenos de crecimiento y desarrollo, especialmente incididos por contextos y preexistencias, como las inequidades espaciales en el desarrollo urbano local, las políticas públicas o su ausencia, entre otros.

En Sudamérica, la tercerización de las economías urbanas y expansión de los servicios, se inicia con especial fuerza en el último tercio del siglo XX, tras la instalación de la visión neoliberal, promoviendo desregulación, privatización y retirada del Estado regulador (Meyer \& Bähr, 2001); aumentando los flujos de capitales internacionales y participación de actores privados en sectores que hasta ese momento eran monopolio del Estado. El resultado, ciudades económicamente más abiertas, cuyas nuevas formas de urbanización y organización fueron respondiendo cada vez más a lógicas neoliberales de comercialización, y generación de valor, que, a la proyección centralizada de un ideario de ciudad (Janoschka, 2002).

Este emergente orden espacio-funcional, fue replicando en las grandes ciudades del continente, parte de las tendencias observadas en los países industrializados (Soja, 2008; Ciccolella, 1999; De Mattos, 1999), produciendo una generalizada metropolización, que pese a sus distingos (Gaussier, Lacour \& Puissant, 2003; De Mattos, 1999; Janoschka, 2002; Borsdorf, 2003), reconoce un estrecha relación entre expansión de actividades económicas terciarias y polinucleación urbana (Aguilar, 2002; Cicolella, 1999; De Mattos, 2002), diluyendo tras de sí las estructuras funcionales de la ciudad tradicional; así, la ciudad nuclear fue dando paso a una metrópolis policéntrica (Janoschka, 2002; Meyer \& Bähr, 2001; Cabrales \& Canosa, 2002), que intensifica los procesos de urbanización, densificando y reestructurando sus núcleos urbanos, al tiempo que se expande, anexando nuevos territorios.

Los discursos académicos sudamericanos, suele coincidir en tres cuestiones que caracterizan el surgimiento y devenir de las estructuras metropolitanas continentales: (i) modernización del comercio detallista, aparición del gran retail, e introducción-apropiación de la tipología shopping mall, posibilitando una descentralización-concentrada del comercio, hacia los pericentros y periferias (De Mattos, 2010; Napadensky, 2012); (ii) desplome de las industrias manufactureras y tercerización de las economías urbanas (Aguilar, 2002), creando, especialmente en las grandes urbes, emergentes distritos de servicios avanzados fuera de los núcleos tradicionales (Chion, 2002; Parnreiter, 2002, 2005, 2011; López Levi, 1997; Ludeña, 2002; Janoschka, 2002; De Mattos, 2010; Ciccolella, 1999; Ducci, 2000); y (iii) obsolescencia de los centros tradicionales, cuestión que suele ser endosado a las dos tendencias antes expuestas (Sarlo, 1994, 2006; Janoschka, 2002; Artigas, et al., 2002; Carman, 2006; López Levi,1997, 1999; Eerola, 2006).

En Chile, aunque persiste una vigorosa actividad industrial, es evidente la desindustrialización urbana en proceso, generando inestabilidad en las economías y mercados laborales locales, especialmente en urbes intermedias, que no son competencia a Santiago, capital nacional y primado centro de servicios terciarios de alto nivel (Escolano, Ortiz \& Moreno, 2007; Escolano y Ortiz, 2004). De este modo, la discusión se centra en el caso del AMC, Chile, sistema urbano intermedio cuyo origen se remonta a mediados del siglo XX. cuando el Estado inició una política de industrialización territorial, localizando aquí industrias tan relevantes como la Empresa Nacional del Petróleo, ENAP, Empresa Nacional de Energía SA, ENDESA, o la Compañía de Aceros del Pacífico, CAP, entre otras.

Así, el trabajo, buscó tensionar los discursos decantados de los estudios e investigaciones que sobre las capitales nacionales, se han ido produciendo, y que suelen reiterar la desconcentraciónconcentrada de los SIC, fuera del centro tradicional y cuyas lógicas de localización están siendo

ACE, 15 (44) CC BY-ND 3.0 ES | UPC Barcelona, España | ¿Un viejo centro, para nuevos usos? Distribución 
incididas, tanto por las sub-centralidades de consumo-ocio previamente emancipadas, como por los distritos industriales ya consolidados, precipitando con ello, estructuras metropolitanas funcionalmente policéntricas.

\section{Caso de estudio y resultados: Área Metropolitana de Concepción (AMC). Región del Bío-Bío, Chile}

La mayor parte de los servicios avanzados a la producción se localizan en Santiago, capital de Chile (Escolano. et al., 2007); y pese a que algunas regiones han profundizado su producciónespecialización, llegando a incrementar servicios comerciales de apoyo, no son un contrapeso a Santiago, capital del país (Escolano \& Ortiz, 2004).

El AMC (Figura 1), es una metrópolis originada por la conurbación de dos ciudades intermedias, Talcahuano y Concepción, siendo esta última capital regional y cabecera de servicios, la cual ejerció, y ejerce, en concomitancia con las discusiones internacionales, un reconocido rol de intermediación entre núcleos más pequeños y grandes ciudades (Michelini \& Davies, 2009), además, ambas: (i) no son capitales nacionales; (ii) articulan el territorio y funcionan como centro de referencia para un territorio inmediato; (iii) son centros de bienes y servicios, más o menos especializados para la población de la misma comuna, y de otros más o menos cercanos; (iv) son centros de interacción social, económica y cultural; (v) están ligadas a redes de infraestructura que conectan redes locales, regionales, nacionales, e incluso internacionales; (vi) articulan flujos; y (vii) alojan niveles de administración del gobierno local, regional y sub-nacional (Llop, 1999). Por tanto, se consideró apropiado hablar de esta metrópolis, como un sistema urbano intermedio.

En la segunda mitad del siglo XX, precipitado tanto por un proceso de industrialización y crecimiento poblacional, como por la conurbación de las comunas centrales, Concepción (CCP) y Talcahuano (THNO), surge el AMC, único sistema urbano en la Región del Bío Bío, que posee un Plan Regulador Metropolitano, cuyo temprano reconocimiento fueron los Planes Reguladores Intercomunales de 1951 y 1963, que regularon el suelo no urbano de las comunas de Concepción y Talcahuano. Desde estas dos primigenias y centrales comunas y sus Planes Intercomunales, la metrópolis ha devenido en un conglomerado de 11 comunas y u millón de habitantes, lideradas por Concepción, una de las ciudades más pobladas del sur de Chile, capital regional y provincial, asiento del poder político regional, sede de ministerios y gobierno regional.

La AMC, se ha venido consolidando y expandiendo, por tres formas primadas; crecimiento por acreción, expansión tentacular y salto de rana (Aliste, Almendras \& Contreras, 2012). Estas, sin embargo, quedan circunscritas en términos generales a una ocupación territorial del tipo dispersión aglomerada (Rojas, Olivera \& García., 2009), que no solo expande la metrópolis, sino también va colmatando sus espacios intersticiales, localizando nuevos tejidos en sus áreas medias (Salinas \& Pérez, 2011). Ya entrado el siglo XXI, es posible apreciar, no sin contradicciones e inestabilidades, una consolidación del sistema metropolitano que, en consonancia con las narrativas académicas imperantes, evidencia marcadas tendencias a la desindustrialización y expansión de su economía de servicios (Napadensky, 2016; Napadensky \& Orellana, 2019b).

La actual AMC, posee 11 comunas, una superficie total de $2.830 \mathrm{~km}^{2}$ y población que supera el millón de habitantes. Sus comunas centrales son; Concepción, con 229.665 hab., y Talcahuano, con 171.332. Las pericentrales; Chiguayante, con 128.110, San Pedro de la Paz, con 98.936, Hualpén, 84.484; y Penco, con 54.102. Luego están las periféricas; Coronel, con 110.623; Lota, con 47.675; Tomé, con 56.410; Hualqui, con 22.880; y Santa Juana; con 13.453. (Figura 1 y 2) 
Figura 1. Ámbito geográfico caso de estudio, AMC, Chile

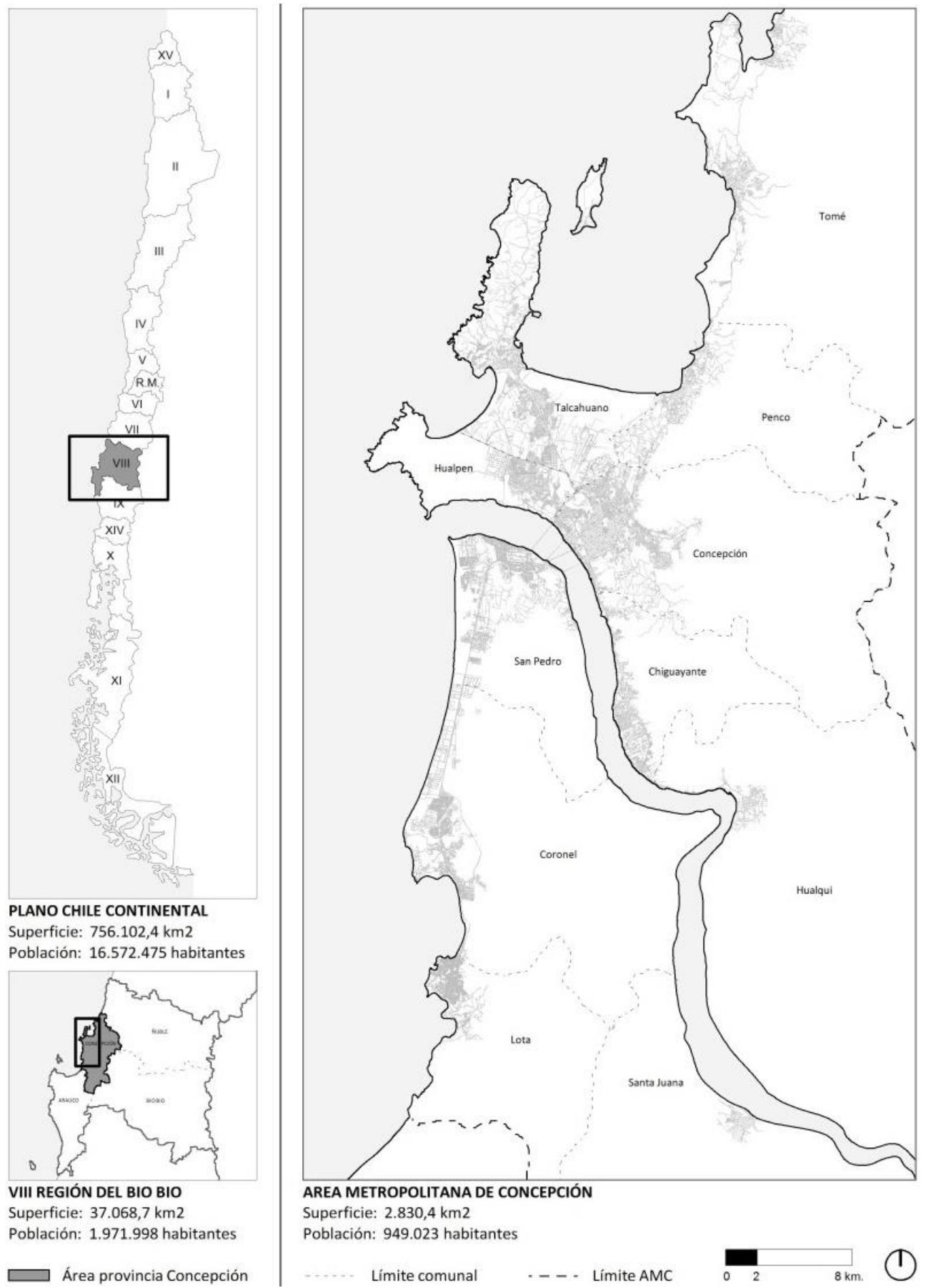

Fuente: Elaboración propia en base a planos del Instituto Geográfico Militar de Chile IGM

\subsection{Una primera mirada a la AMC; SIC O NO-SIC, esa la cuestión}

Las comunas de mayor concentración poblacional son los históricamente centrales, Concepción y, en mucho menor medida, Talcahuano, ya más atrás están los pericentrales; Hualpén, Chiguayante y San Pedro de la Paz. Estas tres últimas comunas, son comunas producto de divisiones de las comunas centrales antes mencionadas, y tienen un marcado rol residencial, concentrando el mayor 
crecimiento habitacional del AMC. Lo relevante, es que estas empiezan a evidenciar actividad comercial y de servicios, incluso de alcance intercomunal, suponiendo la conformación de polos de desarrollo de comercio y servicios que no solo satisfacen los requerimientos intracomunales, sino también metropolitanos; cuestión que disminuye notablemente cuando de las comunas periféricas se trata (Napadensky \& Orellana, 2019b).

Una primera cuestión que es posible inferir a escala metropolitana, son las tendencias de localización de los SIC, las que a grandes rasgos sigue las tendencias de los NO-SIC, al menos cuando la mirada es a escala comunal, sin embargo, dicha tendencia tiende a desacoplarse cuando la mirada sale del núcleo central de las comunas del AMC; por otra parte, ni la población, ni el ingreso por hogar por si solos, resultan suficientes para predecir la concentración de SIC, no al menos en la escala, periodo y área en revisión. (Figura 2). Si, y en términos geográficos con la exactitud que permite la escala, las vialidades estructurantes y las consiguientes condiciones de accesibilidad y visibilidad, parecen jugar un rol relevante en las macro-lógicas de localización y expansión, tanto de los servicios intensivos en conocimiento, como de los no intensivos.

Figura 2. Concentración servicios no intensivos e intensivos en conocimiento [SIC] en AMC, CHILE 2012-2016

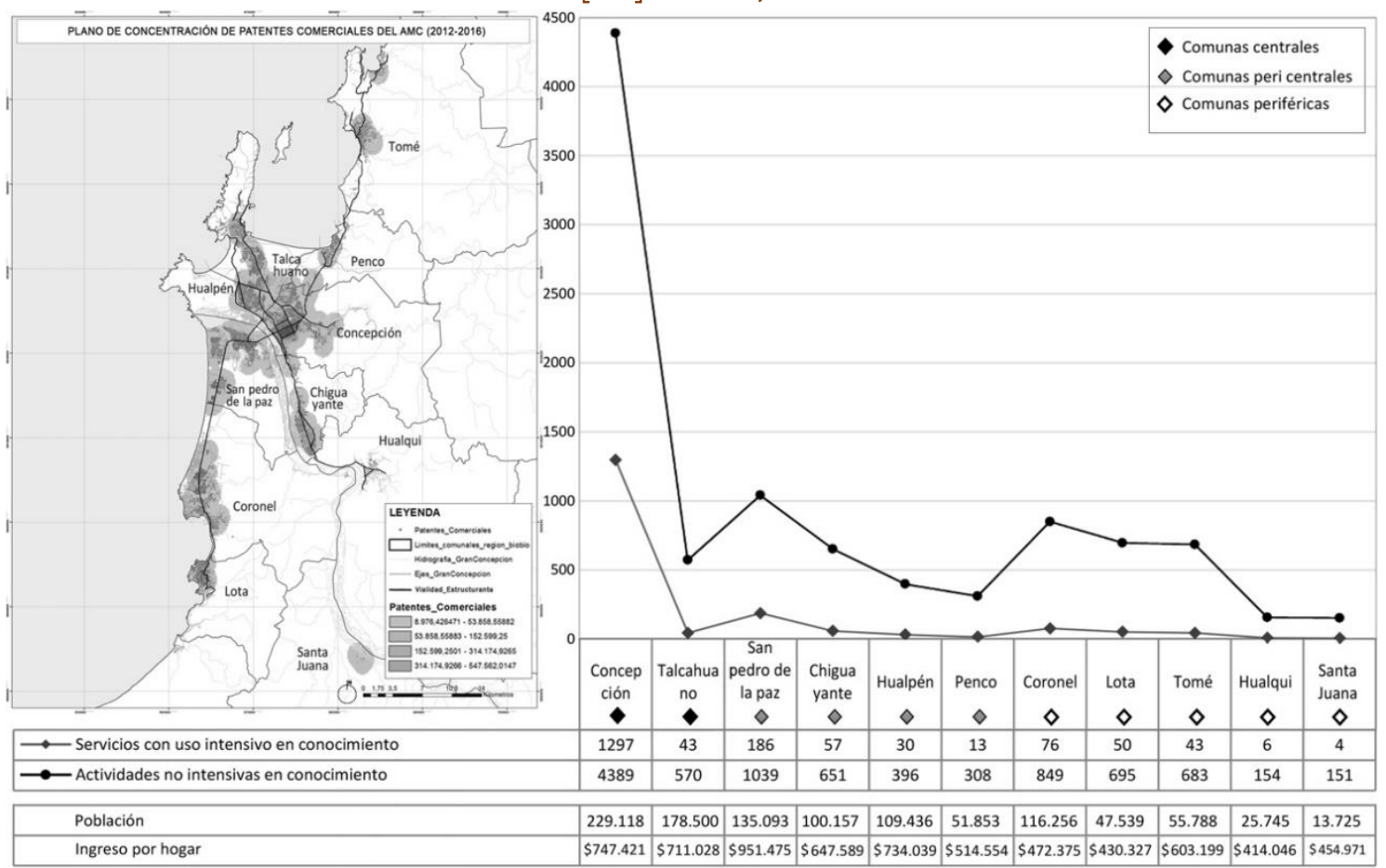

Fuente: Elaboración propia en base a registros de patentes municipales otorgadas entre 2012 y 2016, por los 11 municipios del AMC.

Significativo es que Talcahuano, segunda comuna en importancia poblacional, principal sede de industrias, y parte del núcleo fundante del AMC, pierde relevancia frente a San Pedro de la Paz, comuna relativamente nueva (1994), y con un patrimonio natural y paisajístico significativo (posee la laguna Chica, laguna Grande de San Pedro, río Bio-Bio, humedal Los Batros, único santuario de la naturaleza urbano, importantes cerros y áreas verdes, entre otros atractivos), siendo por lo mismo un importante, atractivo y reciente destino residencial para los grupos de altos ingresos, los que han evidenciado importantes migraciones intermunicipales a su favor (Napadensky \& Orellana, 2019a), dinámica que lo ha alzado, a nivel metropolitano, como la primera comuna en términos de ingresos por hogar, por sobre Concepción y Talcahuano. 
Como se comentaba, la comuna de San Pedro de la Paz, en termino de dinamismo en la concentración de patentes comerciales de SIC, y NO-SIC, se levanta de forma importante por sobre THNO, más no por sobre CCP. En general, la comuna de Talcahuano, en un contexto de desindustrialización avanzado, ha perdido relevancia y atractivo para localizar y expandir una emergente economía de servicios, esto tanto para los NO-SIC, como SIC. Es tanto su pérdida de dinamismo que es superado por comunas pericentrales e incluso periféricas, más alejadas del núcleo metropolitano, como el caso de Chiguayante, Coronel y Lota, con mayor demanda efectiva por patentes SIC. Así, es posible observar, que el histórico núcleo central del AMC, conformado por el eje CCP-THNO, estaría reconfigurándose y siendo relevado por un nuevo eje funcional-terciario, CCP-San Pedro de la Paz. Sin embargo, esta es una inicial observación en merito a los datos aquí analizados, y que habrá que seguir en el tiempo para ratificar dicha tendencia.

\subsection{Una segunda mirada al AMC; SIC, sí, pero donde}

Si bien queda claro en cuáles comunas, en estos en estos cinco años (2012-2016), se han localizado los servicios en general, y los intensivos en conocimiento en particular, la cuestión a discutir ahora es donde, en qué lugares dentro de estas se localizan los SIC, y si están dando lugar a nuevas centralidades, con algún carácter morfológico-estructural distintivo, posible de relacionar a alguna variable urbana, funcional o geográfica singular; ratificando el cambio en el eje de gravedad funcional, que a escala metropolitana, parece esbozarse en una primera vista. O si, por el contrario, son los centros tradicionales los que mantienen su primacía, y de paso rubricando la histórica estructura funcional del bi-núcleo central metropolitano. Para ello, se pone especial atención al área central del AMC, optando por mapear las cuatro categorías que conforman los SIC, es decir, tecnología avanzada (Figura 3), mercado y empresas (Figura 4), otros servicios (Figura 5), y financieros (Figura 6). Agregando las subcategorías de servicios de arquitectura e ingeniera (Figura 4a), y legales (Figura 4b), estas últimas se desagregan para una mayor precisión locacional, dado que se distinguen de las demás por su mayor crecimiento en el periodo registrado.

Los primeros SIC en revisar, fueron los de tecnología avanzada (Figura 3), concentrados en el centro tradicional de la comuna central, CCP, especialmente en torno a la plaza consistorial y las regionales casas matrices de los bancos (DC-38, Intendencia), siendo el microcentro comercial, delimitado por los distritos censales, 67-Plaza España, 38-Intendecia y 68-Plaza Perú, donde se localiza el grueso de estos servicios, siendo débil su expansión hacia el peri-centro. Cabe mencionar que el DC-67, es donde se localiza el gobierno regional, y el DC-60, llamado observatorio, esta flanqueado por la Universidad de Concepción, por el norte y la Avda. y barrio Pedro de Valdivia por el sur. Sin embargo, aparecen incipientes concentraciones en torno al aeropuerto y Shopping Mall Plaza del Trébol (DC-10, Carriel), límite entre las comunas de Talcahuano (THNO) y Concepción (CCP), y otra menor hacia el sur, en la comuna de San Pedro de la Paz, localización coincidente tanto con el edificio consistorial de esta última comuna como por su vialidad estructurante (Avda. Michimalonco-Ruta 160), DC-54, Los Acacios. Talcahuano centro no posee participación en estos servicios (siempre en el arco temporal aquí revisado). Este tipo de SIC presenta una alta concentración, coincidente con los sectores de mayor intensidad peatonal, espacios públicos y otros grandes atractores de viaje de las comunas revisadas.

El segundo tipo de servicios analizados fueron los SIC orientados al mercado y empresas (Figura 4), mucho menos concentrados que los anteriores, pese a ello, es el centro tradicional de CCP y específicamente los DC, 67, 38 y 68, los que estructuran la nueva oferta y localización de estos servicios. Por otra parte, el micro-centro comercial de CCP, en este tipo de SIC, tiende a expandirse hacia el sector oriente, DC-48, 34 y 51, este último, Lopequen, enclave residencial céntrico de altos ingresos; y hacia el sur-oriente, a través del eje vial Avda. Pedro de Valdivia, DC-60, Observatorio, borde sur, donde se ubica el histórico barrio pericentral de altos ingresos, Pedro de Valdivia, eje del 
tradicional cono de alta renta. Otra observación relevante, es su presencia en la comuna de San Pedro de la Paz, concentrándose en los DC, 74 y 54, San Pedro y Los Acacios respectivamente, distritos caracterizados por ser un importante polo de desarrollo de la comuna, en pleno proceso de obsolescencia funcional e invasión-sucesión, donde la residencia va dando paso a comercio y servicios, al menos en sus ejes centrales.

Figura 3. Concentración SIC en tecnología avanzada, comunas centrales AMC.

Figura 4. Concentración SIC orientados al mercado y las empresas, comunas centrales AMC

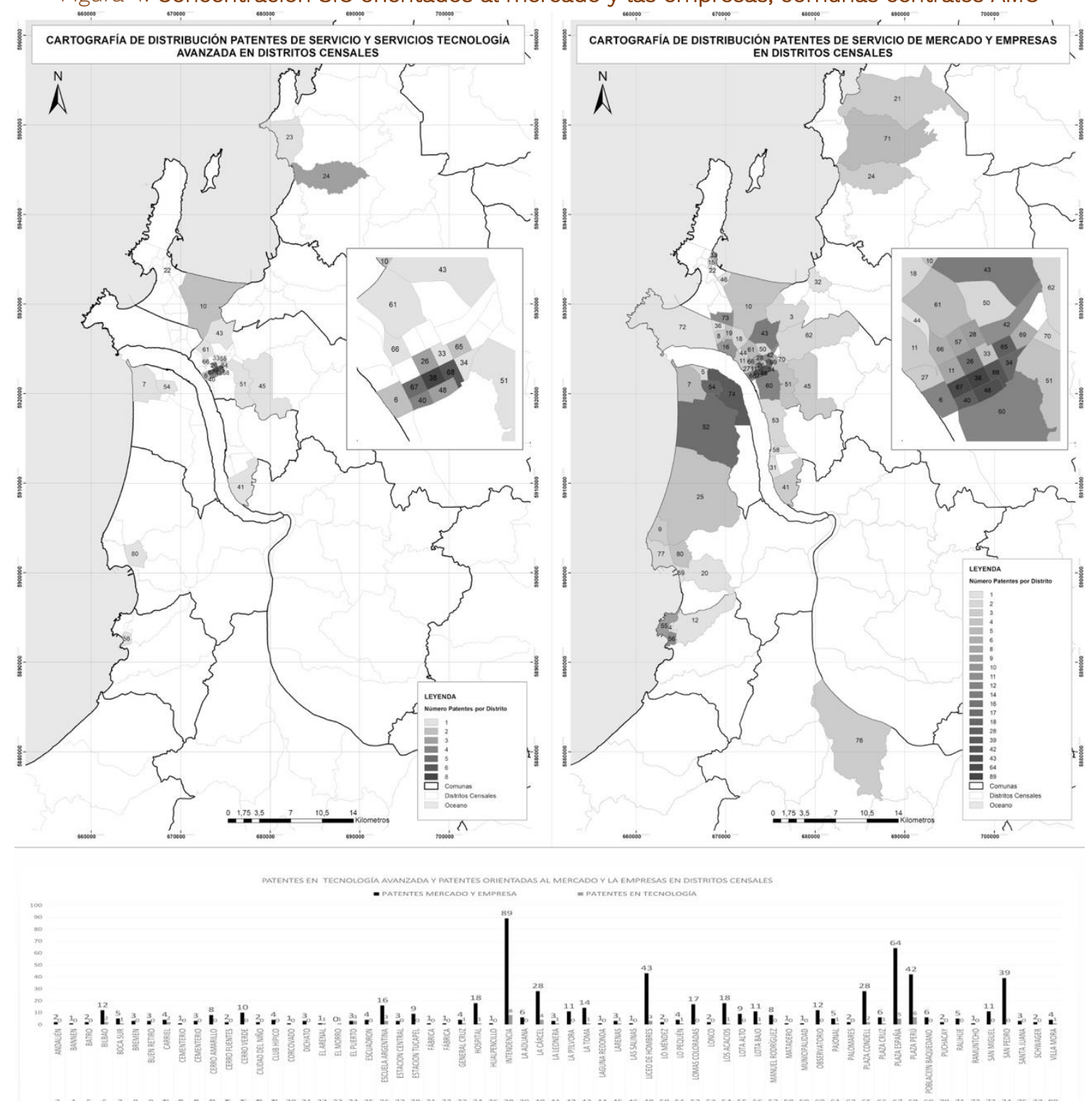

Fuente: Elaboración propia a partir de base de datos con SIC levantada para este estudio, a partir de patentes comerciales efectivamente otorgadas por los municipios del AMC entre el 2012 y 2016.

Como se planteó en la metodología, las categorías SIC, están compuestas de otras tantas subcategorías, y al desagregar estas, se identificó las dos sub-categorías más dinámicas del periodo, ambas pertenecientes a la categoría mercado y empresas, heterogénea en su composición (Cuadro 1). De este modo, se mapeó los servicios de arquitectura e ingeniería (Figura 4a) y los servicios jurídicos y de contabilidad (Figura 4b), y aunque ambos presentan un volumen alto de patentes 
comerciales, se apreciando un patrón de concentración-dispersión, muy desigual, de hecho, estos últimos poseen una mayor y muy intensa concentración espacial en relación a los SIC de arquitectura e ingeniería, quedando circunscritos a pocos distritos centrales, de los centros tradicionales de CCP (DC-68, 34) y San Pedro de la Paz (DC-52).

La arquitectura e ingeniería (Figura 4a), se dispersan con mayor facilidad, y aunque la vialidad estructurante es un factor relevante, su lógica areolar más que lineal, parece responder más a la presencia de universidades (DC, 50, 51, donde se ubican la universidad de Concepción y Bió-Bío, respectivamente), y a barrios de prestigio social, y de estos espacialmente los centrales y pericentrales, particularmente los con alguna identidad urbana, tal es el caso del barrio Universitario (DC-60), Diagonal Pedro Aguirre Cerda (DC-68), Parque Ecuador y Pedro de Valdivia (DC-60); siendo en la práctica, importantes agentes de diversificación de los usos de suelo en el peri-centro de la comuna central, CCP, sin embargo, no evidencian localización que pudiesen asociarse a revitalización y rescate de barrios obsolescentes, en este sentido, su comportamiento locacional, es más bien tradicional y nada arriesgado, privilegiando la cercanía al centro, las densidades peatonales, barrios con identidad y prestigio social.

En los servicios jurídicos y de contabilidad, las aglomeraciones coinciden con pre-existencias temáticamente relevantes, como los tribunales de Justicias (DC-68), juzgados locales (DC-34) y en menor medida conservadores de bienes raíces (DC-54). Otra cuestión relevante a estas importantes aglomeraciones, es que, junto a las preexistencias funcionales antes mencionadas, también coincide con las más relevantes aglomeraciones de cafés y fuentes de soda del AMC (Napadensky, 2016). Así, tribunales de justicia, bufetes de abogados y oficinas de contabilidad, se mezclan con un importante número de cafés, restaurantes y bares diurnos, concentrados en pocas cuadras (DC-68).

Esto no deja de ser interesante en la lógica de posibles complementariedades, vinculados a las dinámicas de funcionamiento de clústers y economías de aglomeración, especialmente relacionadas a las redes formales e informales de información. Esto último habrá que estudiarlo con mayor detenimiento, pero no deja de ser relevante la convergencia de distintos sectores y servicios avanzados y no avanzados en un radio no superior a 5 cuadras; en este sentido, el sector evidencia una tendencia al despoblamiento residencial de los cuerpos edilicios intermedios, producto de la presión de los basamentos comerciales y de servicios que tienden capilarmente a colonizar pisos superiores.

En merito a lo anterior, es posible decir que la concentración espacial que se aprecia en la cartografía Figura 4b, junto con ser la más concentrada de las aquí revisadas, evidencia, o al menos hace plausible pensar que la proximidad física, y con ello, los flujos informales de información y el cara a cara, son factores de relevancia en las lógicas de localización de estos SIC. Por lo mismo, más que una aglomeración, es posible pensar que lo mapeado son cluster jurídicos, especialmente vinculados a empresas contables, no he de olvidarse, que por muy detonada que este la desindustrialización, la industria y empresas siguen teniendo un gran peso en la economía regional, y sobre estos espacios recae mucha de su gestión legal y contable.

Así, y teniendo aun en la retina ambas cartografías (Figura 4a y 4b), es posible atender al hecho que los SIC orientados al mercado y a la empresa, presentan lógicas de localización heterogéneas, y que pueden estar influenciadas por la necesidad o no de constituir cluster, por la necesidad o no del cara a cara y de acceder a los flujos formales, pero especialmente informales de información. Mantenerse en las cercanías y proximidades de los principales centros decisionales de sus respectivos rubros, parece tener una desigual importancia, de ahí la disposición a pagar más por la proximidad y mantenerse dentro de las áreas centrales o no.

ACE, 15 (44.) CC BY-ND 3.0 ES | UPC Barcelona, España | ¿Un viejo centro, para nuevos usos? Distribución 
Figura 4a. Concentración servicios de arquitectura e ingeniería, comunas centrales del AMC Figura 4b. Concentración servicios jurídicos y de contabilidad, comunas centrales del AMC
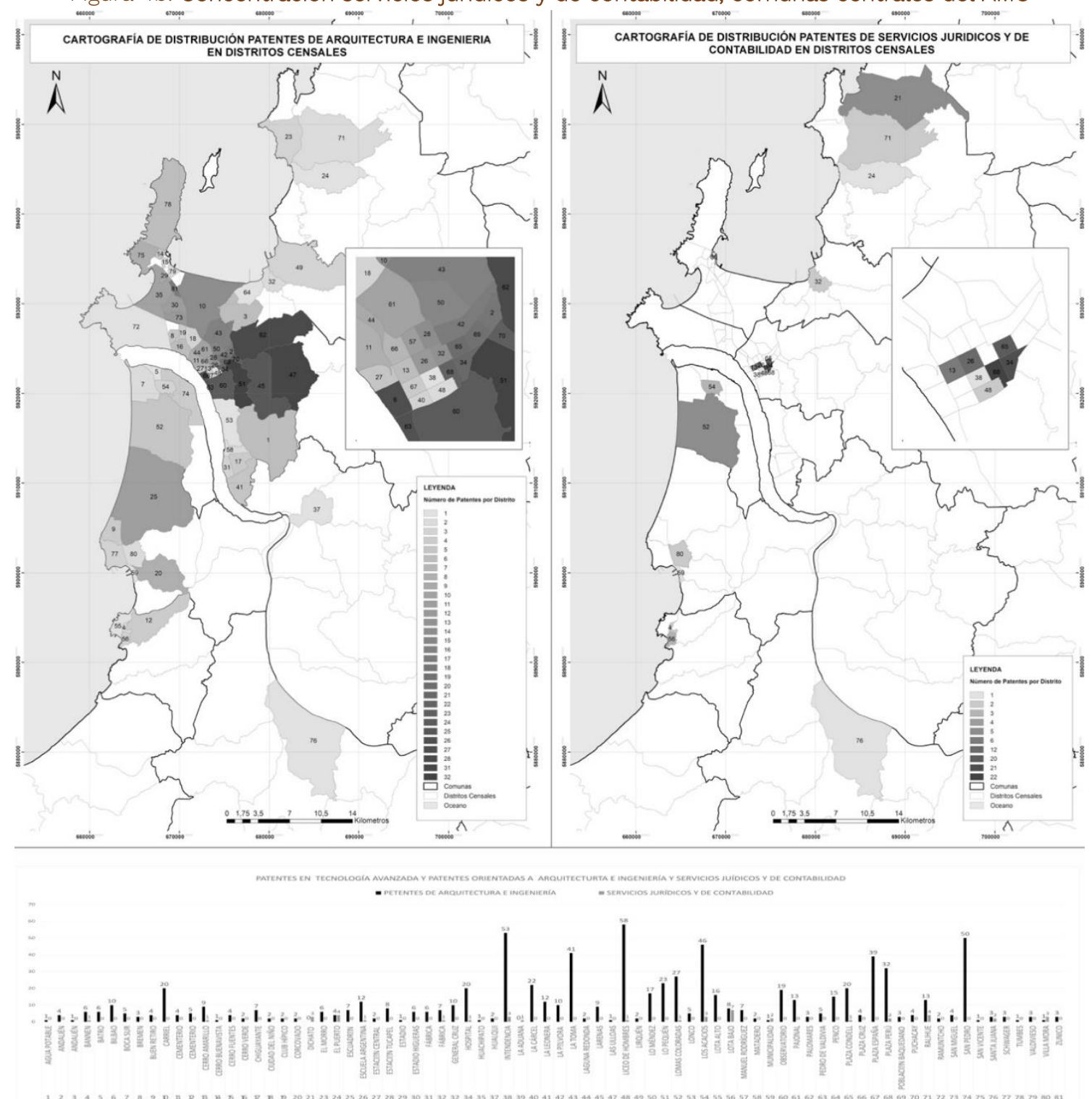

Fuente: Elaboración propia a partir de base de datos con SIC levantada para este estudio, a partir de patentes comerciales efectivamente otorgadas por los municipios del AMC entre el 2012 y 2016.

La tercera categoría revisada es la así llamada Otros servicios intensivos en conocimiento (Figura 5), compuesta por una amplia gama de servicios que van desde actividades de edición, veterinarias, administración pública y defensa, hasta juegos de azar, y entretenimiento (Cuadro 1), la que expone una importante dispersión, pese a ello no mayor a los SIC orientados al mercado y empresa. En el caso de Concepción, Talcahuano, San Pedro y Coronel, y en términos generales dentro del AMC, la poca relevancia en sus tendencias locacionales que evidencian los centros consistoriales de las comunas. Por ejemplo, en Concepción, el DC-51, Lo Pequen, y la nueva centralidad creada en el DC6 , con la construcción de nuevos edificios y equipamientos, que trasladaron el gobierno regional a esta zona próxima al rio Bío Bío (Plan Ribera Norte), y su continuidad hacia el DC-63, borde sur Avda. Pedro de Valdivia, son los principales y más dinámicos distritos en la captación de nuevas localizaciones de estos tipos de SIC. Lo mismo ocurre, pero en menor intensidad, con el DC-25, 
límite entre San Pedro y Coronel, importante polígono industrial del AMC; y en DC-22, en Talcahuano. También marcan los DC-10 y 43, relacionados con el shopping mall Plaza del Trébol y el aeropuerto.

Cuando el foco es el centro tradicional de Concepción y microcentro comercial, nuevamente puede apreciarse como la silueta locacional de esta categoría de SIC, se dilata hacia al Barrio Universitario (DC-60, borde norte) y barrio de Pedro de Valdivia (DC-60, borde sur), y como es el eje vial estructural sur-oriente, Avda. pedro de Valdivia, la que dirige y ordena esta colonización. En el caso de San Pedro de la Paz, el que ordena es el eje vial estructurante que une ambos centros, el de Concepción con San Pedro de la Paz y Coronel, Avda. Michimalonco que luego pasa a llamarse Ruta 160, pero también, y con fuerza, es el barrio de Andalue (sector nuevo de altos ingresos), el que tensiona nuevas localizaciones (DC-52).

Así, es posible hacer una primera y conjunta observación, respecto a estos SIC y cómo son los barrios pericentrales, de altos ingresos, los que suelen tensionar y estructurar una expansión, espacialmente continua, desde los microcentros comerciales, próximos a los polígonos consistoriales, hacia los barrios de altos ingresos contiguos. Es decir, la estructura funcional y su correlato espacial areolar, tiende a dilatarse de forma tentacular, hacia estos barrios, colonizándolos a partir de sus vialidades estructurantes, en un notable proceso de invasiónsucesión, que va simultáneamente, renovando y desplazando la actividad residencial, especialmente en torno a los ejes principales, detonando procesos de obsolescencia económica y mixtura de usos.

La cuarta y última categoría de SIC revisada, fueron los financieros (Figura 6), compuestos por servicios financieros en general, aseguradoras, reaseguradoras y gestión de fondos de pensiones. Su cartografía evidencia concentración, siendo el centro tradicional de Concepción, el que contiene la mayor parte de las localizaciones catastradas (DC-48, 38, 60 y 67), siendo el parque Ecuador, límite sur-poniente del DC-48, un importante atractor de estos SIC. Sin embargo, San Pedro de la Paz, aunque en mucho menor medida, también localiza nuevas iniciativas de este tipo (DC-74). También vuelven a figurar los DC-10 y 43.

La localización de estos servicios, vuelve a dejar en evidencia la vigencia del centro fundacional de Concepción (DC-38, 67), y dentro de éste, la transformación-expansión funcional de su microcentro comercial, hacia el oriente y sur-oriente, siendo el barrio Pedro de Valdivia, particularmente su vialidad estructurante, el que da cuenta del cambio de usos, al menos de los basamentos de casas de primera línea, otrora residenciales (DC-60, limite poniente). Otra expansión relevante de los SIC financieros, es hacia el norponiente, singularmente tensionados por el aeropuerto metropolitano de Carriel Sur y el Mega Shopping Mall de Plaza del Trébol, denotando un cambio de usos de los barrios residenciales de altos ingresos de Lomas de San Andrés, y San Sebastián (DC43). El primero más antiguo y tradicional que el segundo, siendo este último, San Sebastián, un barrio relativamente nuevo que surge por una operación inmobiliaria de gran envergadura, alrededor de una centralidad de nuevo cuño, con diversidad de uso pero sin la proximidad peatonal de los centros tradicionales, conformada por el aeropuerto, Mall Plaza del Trébol, centros de convenciones, universidades, centros de formación técnica, hoteles de cinco estrellas, restaurantes y grandes hipermercados, lo que ha dado gran actividad y dinamismo a este sector intercomunal, donde la actividad residencial vinculada a los ejes viales principales, al poco tiempo ha devenido en obsolescencia económica, dando paso a comercio y servicios, especialmente vinculados al uso de tecnología y plataformas colaborativas, siendo actualmente también un importante polo de hotelería tipo Airbnb (Napadensky \& Villouta, 2019). Pese a ello, estas densidades están más relacionadas al aeropuerto que al centro comercial. 
Figura 5. Concentración de otros servicios intensivos en conocimiento, comunas centrales AMC

Figura 6. Concentración de servicios financieros con uso intensivo en conocimiento, comunas

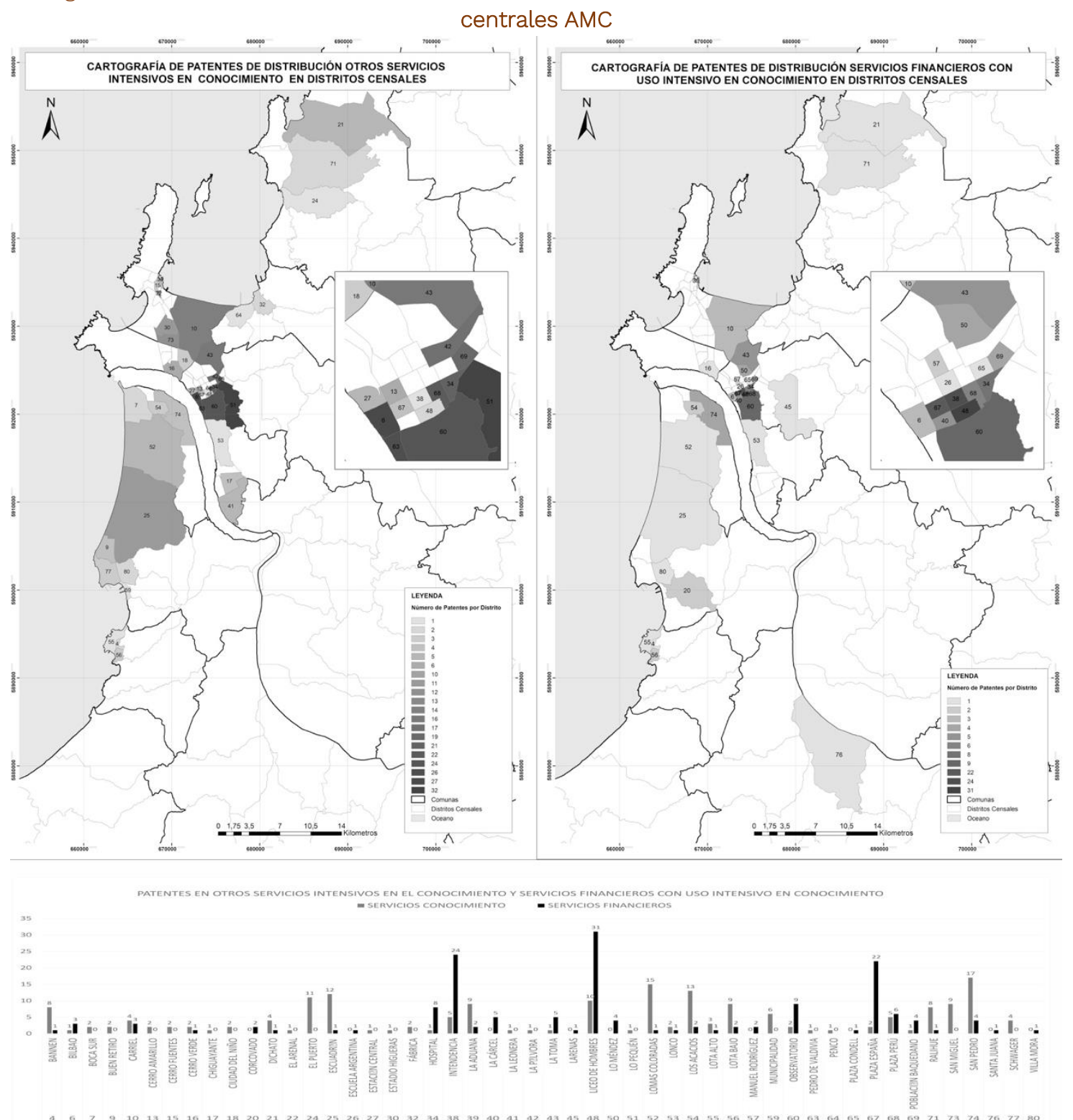

Fuente: Elaboración propia a partir de base de datos con SIC levantada para este estudio, a partir de patentes comerciales efectivamente otorgadas por los municipios del AMC entre el 2012 y 2016.

\section{Conclusiones. Un viejo centro para nuevos usos y algo más}

El presente trabajo planteó indagar si, en el marco de la tercerización de las economías urbanas en general, y expansión de los SIC en sistemas urbanos intermedios en particular, su localización, distribución y concentración, tienden a alinearse con los análisis, discursos, y relativos consensos académicos emanados de los análisis hechos sobre las metrópolis capitales nacionales, o, por el contrario, se deslindan de éstos. Y de haber diferenciación, si estas respondían simplemente a una 
cuestión de orden escalar o estadio evolutivo, o marcaron singularidades que fueran más allá de aquello, haciendo plausible pensar en singulares devenires de estas metrópolis intermedias.

Los resultados expusieron, que, a distinción de la literatura internacional consultada, ni las subcentralidades comerciales, ni las comunas con un alto peso industrial, fueron factores más relevantes que el centro tradicional metropolitano, para explicar el reciente dinamismo y distribución de los SIC en el AMC, siendo los centros tradicionales y barrios de altos ingresos cercanos a estos, los que mejor predijeron su concentración y expansión. En segundo lugar, al parecer, y por lo visto aquí, estos servicios, en contextos de sistemas urbanos intermedios, no serían capaces por si solos de constituir nuevas centralidades o distritos terciarios, usando e intensificando su presencia en los centros tradicionales, ayudando con ello a mantener la condición de centralidad, vigencia y vitalidad de estos, intensificando su rol como centros de comando y control de escala metropolitana y regional, con especial atención a lo visto en el microcentro comercial de Concepción. Aquí se abre una interesante brecha de discusión, dado que es posible apreciar síntomas de una suerte de dualización del centro tradicional metropolitano, es decir, por una parte se expanden los servicios avanzados e intensivos en conocimiento, atrayendo flujos laborales de cuello blanco, y por otro, se expande el comercio detallista de poca monta, precario e informal, mientras el comercio medio y retail de alto nivel ha disminuido, migrando a las grandes superficies comerciales del peri-centro metropolitano.

En tercer lugar, el análisis espacio-locacional realizado sobre de los SIC, dejó a la luz que, junto con privilegiar los centros tradicionales, estos van transformando su estructura funcional, dilatando los micro-centros comerciales y de servicios, especialmente hacia barrios pericentrales con buena accesibilidad, prestigio social y alta renta, resultando en la práctica un factor de invasión-sucesión, renovando, no sin polémica y conflicto, estos barrios; mixturando usos en tejidos antes homogéneamente residenciales. En cuarto lugar, y concatenado con lo anterior, es posible decir que los SIC, en el contexto urbano aquí revisado, no suelen tener capacidad para liderar o apalancar renovaciones urbanas, como si es posible apreciar en otros casos, es decir, los usos de suelo para SIC y el comportamientos de los agentes urbanos detrás de estos, es más bien conservador, estando dispuestos aumentar la capacidad de pago con tal de mantenerse en el centro tradicional, y cuando no, próximos a él, en barrios consolidados y de alto valor de suelo, privilegiándolos por sobre otros barrios pericentrales igualmente bien ubicados, y de menores costos, pero sin prestigio social. Los barrios de altos ingresos, son los ya mencionados Barrio Pedro de Valdivia, Lo Pequen y Barrio Universitario, en las inmediaciones del centro de Concepción, y Andalue, colindante a la centralidad de San Pedro de la Paz.

En cuarto lugar, de las cuatro categorías de SIC revisadas, sin excepción, fue el centro tradicional de la comuna central, CCP, el que concentró la mayor parte de las nuevas localizaciones, dando cuenta de un centro que lejos de entrar en obsolescencia funcional o perder protagonismo frente a otras centralidades, lo mantiene, reinventándose bajo las nuevas lógicas de una economía de servicios y conocimiento, que sigue privilegiando la densidad, proximidad física, el cara a cara y los flujos informales de información. Sin embargo, dentro del propio micro-centro comercial, se aprecian importantes disparidades; mientras los SIC muestran dinamismo en el sector oriente, próximos al Barrio Universitario, Universidad de Concepción, Parque Ecuador, y barrio Pedro de Valdivia, el sector poniente, evidencia avanzados y extendidos procesos de obsolescencia edilicia.

Quinto; de los SIC levantados, algunos serían más sensibles a lo antes descrito que otros, es decir, su localización tendría mayor relación con las cualidades de los tejidos urbanos, espacios públicos, mixturas de usos y equipamientos preexistentes. Esto, en el entendido que dichas características pueden o no facilitar la transferencia y difusión de información y conocimiento (Katz \& Bradley, 2015; Jacobs, 2011). En este sentido, la competitividad de estas aglomeraciones de servicios, también pasa por mantener, potenciar y construir espacios urbanos que den condiciones y

ACE, 15 (44) CC BY-ND 3.0 ES | UPC Barcelona, España | ¿Un viejo centro, para nuevos usos? Distribución 
posibiliten la permanente rúbrica y ampliación de redes formales, y especialmente, informales de información, basadas en interacción persona a persona entre distintos grupos de intereses (Castells \& Hall, 2001; Gertler, et al, 2014; Katz \& Bradley, 2015). Aquí destacaron las aglomeraciones de SIC jurídicos, contables, financieros y en menor medida los de arquitectura e ingeniería.

Lo anterior explica en parte, el interesante paralelismo entre la localización, distribución y concentración de estos SIC, y la presencia de restaurantes, cafés y bares diurnos. Lo que fue particularmente evidente en los servicios intensivos en conocimiento del ámbito jurídico, contable y financiero, los que arrojaron un dinamismo y presencia constitutiva de ecosistemas urbanos densos, que intencionadamente o no, entregan las condiciones para promover y rubricar, tanto las redes formales como informales de información. Cuestión que se vio especialmente alrededor de los Tribunales de Justicia y Diagonal Pedro Aguirre Cerda (DC-68), en el centro de Concepción, donde un detonado proceso de invasión-sucesión, ha venido desplazando otros usos con menor capacidad de pago, como el residencial e incluso servicios menos especializados, fomentando las condiciones para el encuentro, convivencia e interacción de este enjambre de profesionales que es parte del sistema jurídico local, regional y nacional, facilitando la movilidad y trasferencia de conocimiento (Alvim, 2008; Spinosa, Krama \& Hardt, 2018), promoviendo una sinergia que en su accionar sigue atrayendo a nuevos prestadores de este tipo de servicios, haciendo plausible hablar de un clúster jurídico, que aquí queda espacialmente imbricado al clúster contable y financiero. Cuestión que no quedó así claro en otros SIC, como los de arquitectura e ingeniería, los cuales mostraron mayor dispersión por el AMC.

Más allá de estos cinco puntos, un hallazgo relevante ya mencionado, y hasta ahora no documentado, que de hecho no estaba en las intenciones iniciales de esta pesquisa, y que por tanto requerirá mayor estudio, guarda relación con la AMC, cuya descripción como una estructura urbana funcionalmente diversa y de núcleo bi-centrico, conformado por las comunas centrales de CCP y THNO (Vásquez y Salgado, 2009; Rojas, et al., 2009), parece estar cambiando. La evidencia aquí levantada hace viable pensar en una rotación y traslación del histórico eje funcional metropolitano (CCP-THNO), hacia una nueva bi-centralidad, compuesta por el binomio ConcepciónSan Pedro de la Paz, exponiendo el evidente rezago mostrado por Talcahuano.

Lo anterior no deja de ser singular y relevante, dada la discontinuidad que impone el rio Bío-Bío entre ambos núcleos y el fuerte carácter residencial de esta última comuna, misma que, por cierto ha venido recibiendo una importante migración intra-metropolitana, especialmente vinculada a grupos de altos ingresos (Napadensky \& Orellana, 2019a), producto tanto de activos promotores inmobiliarios, que han sabido promocionar y capitalizar los atractivos naturales de San Pedro de la Paz (Laguna Grande, Laguna Chica, Humedal los Batros, y los respectivos parques naturales y santuarios de la naturaleza), como de los grupos locales de altos ingresos, que más alejados de sus predecesores industriales, están más vinculados a una emergente economía terciaria, gustando de la naturaleza como belleza escénica y lugar de práctica de deportes, transformando al paisaje de la comuna en parte del stock de consumo experiencial que caracteriza a estas emergentes elites (Napadensky \& Orellana, 2019a; Napadensky, Villouta \& Farías., 2018). Es decir, este cambio de tendencia en el eje funcional del núcleo metropolitano, vinculado al comportamiento espacial de los servicios intensivos en conocimiento, puede ser explicado en parte, por el cambio en las tendencias locacionales de las elites, y esto a su vez por sus emergentes gustos y necesidades hedónicas, vinculadas a la naturaleza como objeto de contemplación e inmersión experiencial.

Ambas cuestiones aquí descritas, y vistas en distintas escalas de análisis son relevantes. Es decir, y en la escala comunal, resultó significativo como los SIC intensifican, vitalizan y dan vigencia a los centros tradicionales de Concepción y San Pedro de la Paz, eso sí, de forma no homogénea, marcando, según el tipo de SIC, mayor sensibilidad a unas cualidades urbanas que otras, al tiempo que expanden las áreas de los microcentros comerciales y de servicios hacia barrios colindantes de

ACE, 15 (44) CC BY-ND 3.0 ES | UPC Barcelona, España | ¿Un viejo centro, para nuevos usos? Distribución 18 espacial de Servicios Intensivos en Conocimiento [SIC] en el Área Metropolitana de Concepción [AMC], Chile. DOI: http://dx.doi.org/10.5821/ace.15.44.9210 
altos ingresos, profundizando una dualización y asimetría entre áreas bien equipadas y florecientes, y otras en franca obsolescencia. En la escala metropolitana, estas tendencias locacionales aquí descritas, dan evidencias en favor de un cambio en el histórico eje funcional del bi-núcleo metropolitano, desde el inicial eje oriente-poniente que unía los centros tradicionales de Concepción y Talcahuano, a otro de nuevo cuño, norte-sur, que une a esta primada comuna, Concepción, con la emergente San Pedro de la Paz. No obstante, estos hallazgos habrá que seguir estudiándolos y confirmándolos en lo sucesivo. Contrastándolo con el otro eje de servicios, marcado por el Shopping Mall Plaza del Trébol y el Aeropuerto (DC-43), que también evidencia un dinamismo que no mayor a los centros tradicionales, es significativo y marca un segundo núcleo metropolitano en formación (Napadensky \& Villouta, 2019).

Habrá que seguir profundizando en las tendencias identificadas, tanto en la escala comunal como metropolitana, especialmente en el contexto de sistemas urbanos intermedios, donde aún son vigentes los procesos de desindustrialización y notables las desventajas que enfrentan para la expansión y consolidación de una economía del conocimiento. Siendo en este sentido, vital el repensar sus competitividades y estrategias de posicionamiento global, desde lo local, estando obligadas a ir más allá de políticas ancladas a la atracción de inversión, incentivos tributarios y subvenciones, (González, 2012; Méndez, Michelini \& Romero, 2006; Méndez, Michelini \& Prada, 2012), instalando una discusión necesaria sobre la imbricación entre política de competitividad urbana, diseño urbano y potenciamiento de los atractivos propios de estos sistemas, abriendo un espacio para pensar la ciudad desde su morfología, geografía, paisajes, mixtura de usos, espacios públicos y amenidades, identificando lineamientos que en estas cuestiones promuevan el desarrollo de entornos urbanos cuyas características incrementen las conexiones y flujos de información, formal e informal, entre los distintos actores vinculados al conocimiento, propiciando el desarrollo de clúster más competitivos y atractivos (Gertler, et al., 2014; Katz \& Bradley, 2015), fomentando así, ecosistemas urbanos densos en información y conectados para su amplio flujo, propiciando la innovación y proliferación de servicios intensivos en conocimiento, motores de un desarrollo económico de nuevo cuño que llego para quedarse.

\section{Agradecimientos}

El autor agradece a la Vicerrectoría de Investigación y Postgrado de la Universidad del Bío Bío, y su apoyo económico para la investigación, en el marco del proyecto Grupo de Investigación Gl 195501/EF. A los arquitectos, Paulina Vargas y Juan Soto, por su participación como ayudantes de investigación y gran contribución en el trabajo de terreno. Al Laboratorio de Estudios Urbanos, LEU, por su aporte al desarrollo cartográfico. Y a los 11 municipios que aportaron información para esta pesquisa.

Conflicto de intereses: El autor declara que no hay conflicto de intereses.

\section{Bibliografía}

Aguilar, A. (2002). Megaurbanization and Industrial Relocation in Mexico Central Region. Urban Geography, 23(7), 649-673. DOI: http://dx.doi.org/10.2747/0272-3638.23.7.649

Aliste, E., Almendras, A. \& Contreras, M. (2012). La dinámica del territorio en la conurbación Concepción-Talcahuano: huellas urbanas para una interpretación de las transformaciones ambienta- les durante la segunda mitad del siglo XX. Revista de Geografía Norte Grande, (52), 5-18. DOI: http://dx.doi.org/10.4067/S0718-34022012000200001 
Artigas, A., Chabalgoity, M., García, A., Medina, M. \& Trinchitella, J. (2002). Transformaciones socioterritoriales del Área Metropolitana de Montevideo. EURE, 28(85), 151-170. DOI: http://dx.doi.org/10.4067/S0250-71612002008500008

Alvim, A. (2008). Novas congurações produtivas como estratégias de desenvolvimento local: perspectivas ao planejamento urbano. Exacta, 6(1), 157-168, 2008. DOI: http://dx.doi.org/10.5585/exacta.v6i1.809

Berry, C. y Glaeser, E. (2005). The Divergence of Human Capital Levels across Cities. Regional Science, 84(3), 407-444. DOI: https://doi.org/10.1111/j.1435-5957.2005.00047.x

Borsdorf, A. (2003). Como modelar el desarrollo y la dinámica de la ciudad latinoamericana. EURE, 29(86), 37-49. DOI: http://dx.doi.org/10.4067/S0250-71612003008600002

Brenner, N. \& Theodore, N. (2002) (eds.) Space of Neoliberalism: Urban Restructuring in North America and Western Europe. Oxford, UK: Wiley-Blackwell. DOI: http://dx.doi.org/10.1016/S0962$\underline{6298(03) 00121-5}$

Cabrales, L. \& Canosa E. (2002). Nuevas formas y viejos valores: urbanizaciones cerradas de lujo en Guadalajara. Cabrales, L. (ed.), Latinoamérica: Países abiertos, ciudades cerradas. Universidad de Guadalajara/UNESCO, Guadalajara, 93-117. Recuperado de http://digital-library.unesco.org/shs/most/ gsdl/cgi-bin/library?e=d-000-00---0most--00-0-0--0prompt-10---4------0-1l--1-en-50---20-about ---00031-001-1-0utfZz-8-00\&a=d\&c=most\&cl=CL3.2\&d=HASHd876132828a9a2edecd368

Carman, M. (2006) Las trampas de la cultura. Buenos Aires, Argentina: Paidós.

Castells, M. \& Hall, P. (2001) Tecnópolis del mundo. La formación de los complejos industriales del siglo XXI. Madrid, España: Alianza Editorial.

Ciccolella, P. (1999). Globalización y dualización en la Región Metropolitana de Buenos Aires: Grandes inversiones y reestructuración socioterritorial en los años noventa. EURE, 25(76), 5-27. DOI: http://dx.doi.org/10.4067/S0250-71611999007600001

Costas, P. (2008). Creativity, innovation and territorial agglomeration in cultural actvities: Theroots of the creative city. En: Cooke, P. \& Lazzeretti-Cheltenham, L., (Eds.). Creative cities, cultural clusters and local economic development. UK: Edward Elgar Publishing Ltd. Recuperado de https://www.eelgar.com/shop/gbp/creative-cities-cultural-clusters-and-local-economic-development$\underline{9781847202680 . h t m l}$

Chica, E. \& Marmolejo, C. (2011). Los sectores económicos intensivos en conocimiento y sus formas de localización en el territorio metropolitano: un estudio para la región metropolitana de Barcelona. ACE: Arquitectura, Ciudad y Entorno. 6(16), 223-252. DOI: http://dx.doi.org/10.5821/ace.v6i16.2525

Chion, M. (2002). Dimensión metropolitana de la globalización: Lima a fines del siglo XX. EURE, 28(85), 71-87. DOI: http://dx.doi.org/10.4067/S0250-71612002008500005

De Mattos, C. (1999). Santiago de Chile, globalización y expansión metropolitana: lo que existía sigue existiendo. EURE, 25(76), 29-56. DOI: http://dx.doi.org/10.4067/S0250-71611999007600002

De Mattos, C. (2002). Mercado metropolitano de trabajo y desigualdades sociales en el Gran Santiago: ¿una ciudad dual? EURE, 28(85), 51-70. DOI: http://dx.doi.org/10.4067/SO250$\underline{71612002008500004}$

De Mattos, C. (2010). "Globalización y metamorfosis metropolitana en América Latina: de la ciudad a lo urbano generalizado". Revista de Geografía Norte Grande, (47), 81-104. DOI: http://dx.doi.org/10.4067/s0718-34022010000300005 
Diez, J. \& Emilozzi, A. (2015). Redes organizacionales y desarrollo económico en ciudades medias: los casos Bahía Blanca y Río Cuarto. Cuaderno urbano, 18(18), 21-48. DOI: http://dx.doi.org/10.30972/crn.1818262

Ducci, M. (2000). Santiago: territorios, anhelos y temores. Efectos sociales y espaciales de la expansión urbana. EURE, 26(79), 5-24. DOI: http://dx.doi.org/10.4067/S0250-71612000007900001

Eerola, T. (2006). Shopping centers: a construção de territórios de consumo na pósmodernidade. El Norte - FinnishJournal of Latin American Studies, (1), 1-16. Recuperado de https://www.academia.edu/4163351/Shopping Centers a construção de territórios de consumo n a pós modernidade

Eurostat Regional YearBook. (2014) Luxembourg: Publications Office of the European Unión. https://ec.europa.eu/eurostat/documents/3217494/5785629/KS-HA-14-001-EN.PDF

Escolano, S. \& Ortiz, J. (2004). La complejidad de los procesos de reestructuración socioespacial de las ciudades intermedias: persistencia y cambio en la ciudad de Puerto Montt (Chile). Anales de Geografía de la Universidad Complutense, https://revistas.ucm.es/index.php/AGUC/article/view/AGUC0404110079A

Escolano, S., Ortiz, J. \& Moreno, R. (2007). Globalización y cambios funcionales recientes en las ciudades del sistema urbano chileno. Cuadernos Geográficos, (41), 33-60. https://revistaseug.ugr.es/index.php/cuadgeo/article/view/1146

Florida, R. (2010) La clase creativa. La transformación de la cultura del trabajo y el ocio en el siglo XXI. Barcelona, España: Paidós.

García, B. (2008). Política cultural y regeneración urbana en las ciudades de Europa occidental: lecciones aprendidas de la experiencia y perspectivas para el futuro. Revista de Investigaciones Políticas y Sociológicas, 7(1), 111-125. http://hdl.handle.net/10347/8337

Garreau, J. (1991). Edge City. Life on the new frontier. New York, EEUU: Doubleday.

Gaussier, N., Lacour, C. \& Puissant, S. (2003). Metropolitanization and territorial scales. Cities, 20(4), 253-263. DOI: http://dx.doi.org/10.1016/S0264-2751(03)00032-5

Gertler, M. and Vinodrai, T. (2005). Anchors of creativity: How do public universities create competitive and cohesive communities? En: Lacobucci, F. and Tuohy, C, eds. Taking Public Universities Seriously. Toronto, University of Toronto Press. 293-315. DOI: http://dx.doi.org/10.3138/9781442680333

Gertler, M. Geddie, K. Hatch, C. \& Rekers, J. (2014). Attracting and RetainingTalent: Evidence from Canada's City-Regions. Grant, Jill (Ed.). Seeking Talent for Ceative Cities. Toronto, Canada: University of Toronto Press. Recuperado de https://www.jstor.org/stable/10.3138/j.ctt5vkjkj

González, D. (2012). Competitividad y estrategias de desarrollo. En Santiago de Chile: una ciudad atractiva para un país competitivo. De Mattos, C. Bannen, P. \& Fuentes, L. (Eds). Santiago, Chile: Colección Estudios Urbanos Universidad Católica. Recuperado de https://estudiosurbanos.uc.cl/libro /santiago-de-chile-una-ciudad-atractiva-para-un-pais-competitivo/

Harvey, D. (2005) A Brief History of Neoliberalism. Oxford: Oxford University Press.

Howkins, J. (2001) The Creative Economy: How People Make Money from Ideas. London, New York: Penguin Press. Recuperado de https://www.penguin.co.uk/books/196/196214/the-creativeeconomy/9780141977034.html 
Hoyman, M. \& Faricy. C. (2008). It Takes a Village: A Test of the Creative Class, Social Capital and Human Capital Theories. Urban Affairs Review, 44(3), 311-333. DOI: https://doi.org/10.1177\%2F1078087408321496

Jacobs, J. (2011) Muerte y vida de las grandes ciudades. Madrid, España: Capitán Swing Libros.

Janoschka, M. (2002). Urbanizaciones privadas en Buenos Aires: ¿hacia un nuevo modelo de ciudad latinoamericana? Cabrales, L. (ed.), Latinoamérica: Países abiertos, ciudades cerradas. Guadalajara, México: Universidad de Guadalajara/UNESCO, 287-318. Recuperado de http://digital-library.unesco.or $\mathrm{g} / \mathrm{shs} / \mathrm{most} / \mathrm{gsdl} / \mathrm{cgi-bin} /$ library?e=d-000-00---0most--00-0-0--0prompt-10---4------0-1L--1-en-50 ---20-about---00031-001-1-0utfZz-8-00\&a=d\&c=most\&cl=CL3.2\&d=HASHd876132828a9a2edecd368

Jurarte, C. (2011). Mapping Vilnius as creative city. LIMES: Borderland Studies, 4 (1), 89-100. DOI: https://doi.org/10.3846/20290187.2011.577141

Katz, B. \& Bradley, J. (2015) The Metropolitan Revolution. How Cities and Metros Area Fixing Our Broken Politics and Fragile Economy. Washintong, United State: Ed. The Brookings Institution. Recuperado de https://www.brookings.edu/book/the-metropolitan-revolution-2/

Krätke, S. (2011) The Creative Capital of Cities: Interactive Knowledge Creation and the Urbanization Economies of Innovation. Wiley-Blackwell. Recuperado de https://www.wiley.com/enus/9781444336214

López-Levi, L. (1997). Los centros comerciales como espacios multifuncionales. Argumentos, (27), 81-96. Recuperado de https://argumentos.xoc.uam.mx/index.php/argumentos/article/view/688

López-Levi, L. (1999). Centro comerciales. Espacios que navegan entre la realidad y la ficción. Ciudad de México, México: Nuestro tiempo. Recuperado de https://www.academia.edu/768920/Cent ros comerciales Espacios que navegan entre la realidad y la ficción

Ludeña, W. (2002). Lima: poder, centro y centralidad: Del centro nativo al centro neoliberal. EURE, 28 (83), 45-65. DOI: http://dx.doi.org/10.4067/S0250-71612002008300004

Llop, J. (1999). Ciudades intermedias y urbanización mundial. Lleida, España: Unión Internacional de Arquitectos, UIA, UNESCO. Recuperado de http://www.ceut.udl.cat/wp-content/uploads/5.BOOK1 .pdf

Martinelli, F. \& Cavola, L. (2002). The influence of regional demand and institutions on the role of KIS. En Wood, P. (Ed.) Consultancy and Innovation. London, Reino Unido: Routledge. DOI: https://doi.org/10.4324/9780203116647

Méndez, R.; Michelini, J., \& Romero, P. (2006). Redes socioinstitucionales e innovación para el desarrollo de las ciudades intermedias. En Ciudad y Territorio Estudios Territoriales, 38(148), 337395. Recuperado de https://recyt.fecyt.es/index.php/CyTET/article/view/75683

Méndez, R., Michelini, J., Prada, J., \& Tebar, J. (2012). Economía creativa y desarrollo urbano en España: una aproximación a sus lógicas espaciales. EURE. 38(113), 5-32. DOI: http://dx.doi.org/10.4067/S0250-71612012000100001

Meyer, K. \& Bähr, J. (2001). Condominios in Greater Santiago de Chile and their Impact on the Urban Structure. Die Erde, 132(3). Recuperado de http://pascalfrancis.inist.fr/vibad/index.php?action=getRecordDetail\&idt=14319489

Michelini, J. \& Davies, C. (2009). Ciudades intermedias y desarrollo territorial: un análisis exploratorio del caso argentino. Gedeur, (5), 1-26. Recuperado de https://flacso.edu.ec/cite/media/2016/02/Michelini J et al 2009 Ciudades intermedias y desarroll o territorial un analisis exploratorio del caso argentino1-1.pdf 
Muller, E. \& Zenker, A. (2001). Business services as actors of know ledge transformation: the role of KIBS in regional and national innovation systems. Research Policy, Vol. 30(9), 1501-1516. Recuperado de http://www.sciencedirect.com/science/article/pii/S0048-7333(01)00164-0

Muñiz-Olivera, I. \& García-López, M. (2009). Policentrismo y sectores intensivos en información y conocimiento. Ciudad y Territorio Estudios Territoriales (CYTET), 41(160), 263-289. Recuperado de https://recyt.fecyt.es/index.php/CyTET/article/view/75925

Napadensky, A. (2012). Los grandes agentes del retail en la construcción de la urbanidad metropolitana neoliberal. El caso del shopping mall Parque Arauco en Santiago de Chile. 1982-2012. Cuadernos de vivienda y Urbanismo. Separata: X Seminario Investigación Urbana y Regional. Recuperado de https://revistas.javeriana.edu.co/index.php/cvyu/article/view/5473

Napadensky, A. (2016). Centros tradicionales, nuevas centralidades y descentralización en metrópolis intermedias latinoamericanas: caso del Gran Concepción, Chile. Cuaderno Urbano, 21 (21): 29-56. DOI: http://dx.doi.org/10.30972/crn.21211177

Napadensky, A., Villouta, D. \& Farias, F. (2018) Ciudad para creativos: lo que atrae y repele del Gran Concepción, Chile. Disonancias entre discursivas globales y locales. ACE: Arquitectura, Ciudad y Entorno, 13(37), 241-268, DOI: http://dx.doi.org/10.5821/ace.13.37.5276

Napadensky, A., \& Villouta, D. (2019). Plataformas tecnológicas colaborativas: Entre la ciudad imaginada de la tradición y la reorganizada tras la innovación. AUS [Arquitectura / Urbanismo / Sustentabilidad], (26), 42-50. DOI: https://doi.org/10.4206/aus.2019.n26-08

Napadensky, A. \& Orellana, A. (2019a). Atractivos paisajísticos y dispersión residencial de grupos de altos ingresos: ¿una nueva élite de consumidores experienciales? Caso Gran La Serena y Gran Concepción, Chile, 1965-2012. Revista 180, (43), 101-114. DOl: https://dx.doi.org/10.32995/rev180.num43.(2019).art-608

Napadensky, A. \& Orellana, A. (2019b). Metropolización y organización funcional de sistemas urbanos intermedios. Gran La Serena, Concepción y Puerto Montt. Bitácora Urbano Territorial, 29(1), 65-78. DOI: https://dx.doi.org/10.15446/bitacora.v29n1.67325

Parnreiter, C. (2011). Formación de la ciudad global, economía inmobiliaria y transnacionalización de espacios urbanos. El caso de Ciudad de México. EURE, 37(111), 5-24. DOI: http://dx.doi.org/10.4067/S0250-71612011000200001

Parnreiter, C. (2005). Tendencias de desarrollo en las metrópolis latinoamericanas en la era de la globalización: los casos de Ciudad de México y Santiago de Chile. EURE, 31(92), 5-28. DOI: http://dx.doi.org/10.4067/S0250-71612005009200001

Parnreiter, C. (2002). Ciudad de México: el camino hacia una ciudad global. EURE, 28(85), 89-119. DOI: http://dx.doi.org/10.4067/S0250-71612002008500006

Peck, J. (2005). Struggling with the creative class. International Journal of Urban and Regional Rsearch, 24(4). DOI: https://doi.org/10.1111/j.1468-2427.2005.00620.x

Pratt, A. (2008). Creative cities: the cultural industries and the creative class. Geogra- fiska annaler: Series B - Human geography, 90(2). DOI: https://doi.org/10.1111/j.1468-0467.2008.00281.x

Rojas, C., Olivera, I. \& García, M. (2009). Estructura urbana y policentrismo en el Área Metropolitana de Concepción. Eure, 35(105), 47-70. DOI: http://dx.doi.org/10.4067/S0250-71612009000200003 
Salinas, E. y Pérez, L. (2011) Procesos urbanos recientes en el Área Metropolitana de Concepción: transformaciones morfológicas y tipologías de ocupación. Revista de Geografía Norte Grande, (49), 79-97. DOI: http://dx.doi.org/10.4067/S0718-34022011000200006

Sánchez, S. (2012). El empleo en la economía del conocimiento en España: características socioprofesionales y patrones de distribución territorial. Scripta Nova. (16), 399. Recuperado de http://www.ub.edu/geocrit/sn/sn-399.htm

Sassen, S. (1996) Cities and Communities in the Global Economy: Rethinking Our Concepts. American Behavioral Scientist, 39(5), 629-639. DOI: https://doi.org/10.1177\%2F0002764296039005009

Sarlo, B. (1994) Escenas de la vida posmoderna. Buenos Aires, Argentina: Seix Barral.

Sarlo, B. (2006) Tiempo Presente: notas sobre el cambio de una cultura. Buenos Aires, Argentina: Siglo XXI.

Soja, E. (2008) Postmetrópolis. Estudios críticos sobre las ciudades y las regiones. Madrid, España: Traficantes de Sueños.

Spinosa, L., Krama, M., \& Hardt, C. (2018) Desarrollo urbano basado en el conocimiento y ecosistemas de innovación urbana: un análisis en cuatro ciudades brasileñas. EURE, 44(131), 193-214. DOI: http://dx.doi.org/10.4067/S0250-71612018000100193

Throsby, D. (2004). Assessing the Impacts of a Cultural Industry. Journal of Arts Management. Law and Society, 34(3), 188-204. DOI: https://doi.org/10.3200/JAML.34.3.188-204

Throsby, D. (2008). Modelling the cultural industries. International Journal of Cultu ral Policy. 14(3), 217-232. DOI: https://doi.org/10.1080/10286630802281772

Vásquez, A., \& Salgado, M. (2009). Desigualdades socioeconómicas y distribución inequitativa de los riesgos ambientales en las comunas de Peñalolén y San Pedro de la Paz: Una perspectiva de justicia ambiental. Revista de Geografía Norte Grande, (43), 95-110. DOI: http://dx.doi.org/10.4067/S0718$\underline{34022009000200006}$

Vecslir, L., \& Ciccolella, P. (2011) Relocalización de las actividades terciarias y cambios en la centralidad en la Región Metropolitana de Buenos Aires. Revista de Geografía Norte Grande. (49), 6378. DOI: http://dx.doi.org/10.4067/S0718-34022011000200005

Veltz, P. (1994) Jerarquías y redes en la organización de la producción y el territorio. Benko, G. y Lipietz, A. (Eds.) Las regiones que ganan. Valencia, España: Edicions Alfons el Magnanim.

Vence, X. Y Rodil, O. (2003). La concentración regional de la política de I+D de la Unión Europea: el principio de cohesión en entredicho. Revista de Estudios Regionales. 65. Recuperado de https://www.redalyc.org/pdf/755/75506502.pdf

Vence, X. (2007). La tercerización y metropolización de la economía mundial: una aproximación a partir de las tendencias en la Unión Europea. En IX Reunión de Economía Mundial. Madrid.

Wolfe, D. y GERTLER, M. (2004). Cluster from the inside and out: Local dynamics and global linkages. Urban Studies, 41 (5-6): 1071-93. DOI: http://dx.doi.org/10.1080/00420980410001675832 